\title{
INFRASTRUCTURE MAINTENANCE IN THE IRRIGATION DISTRICTS OF MEXICO
}

\author{
LOMELI V. RAMÓN ${ }^{1} \&$ ALVAREZ G. NAZARIO ${ }^{2}$ \\ ${ }^{1}$ Instituto Mexicano de Tecnología del Agua, Mexico \\ ${ }^{2}$ Comisión Nacional del Agua, Mexico
}

\begin{abstract}
In Mexico, the surface area dedicated to agriculture is approximately $21,000,000$ hectares $(51,892,130$ acres); of that, $6,400,000(15,814,744$ acres $)$ are accounted for by irrigation infrastructure and 3,500,000 $(8,648,688$ acres) correspond to 86 irrigation districts. Irrigated farming generates more than half of the national agricultural production, using infrastructure in good working order through maintenance work carried out at the required frequency. The main problems of infrastructure maintenance are the accumulation of sediments, terrestrial and aquatic weed, shape and conformation roads, and electromechanics and civil works in structures. The present work analyses the main maintenance works, the distribution of costs of infrastructure maintenance and the general impact of the maintenance works on the irrigation districts' productivity.
\end{abstract}

Keywords: irrigation districts maintenance, irrigation districts productivity.

\section{INTRODUCTION}

Mexico ranks seventh worldwide in agricultural production infrastructure, with 6,400,000 hectares $(15,814,744$ acres $)$ comprising irrigation infrastructure. Only this surface area of the $21,000,000$ to $24,000,000$ hectares $(51,892,130$ to $59,305,291$ acres $)$ cropped annually are irrigated; the remaining hectares are dry lands. However, over half of the country's income derived from agriculture comes from the irrigated land.

Irrigated lands are grouped in 86 irrigation districts, and approximately 27,000 small irrigation districts. Highlights the contribution of the 86 irrigation districts with $£ 105,066$ million and a production value of $€ 6267$ million [1].

\section{DIAGNOSIS}

In Mexico, there are 1471 basins, organized in 37 hydrologic regions, and grouped into 13 hydrological-administrative regions.

The normal rainfall is 30 inches (normal values, according to the World Meteorological Organization); on average, $68 \%$ of the normal monthly rainfall occurs between June and September [2].

There are more than 4462 dams, 667 (classified as large dams, according to the definition of the International Commission on Large Dams) and more than 1085 small dams [2]. The storage capacity of the dams is about $1,230,000,000,000 \mathrm{yd}^{3}$ depending of rainfall and runoff in different regions of the country, as well as the dams operating policies, determined by the storages objectives.

The development of surface irrigation in Mexico is limited, and currently, there are few sources of water economically available, therefore, to maintain or improve the productivity of the irrigation district is priority for optimal maintenance of infrastructure

The maintenance of the infrastructure is basic to improve the operation of the irrigation districts and to fulfil with the irrigation schedule. In Mexico, to make quick and economical field work, we use manpower, heavy weight machinery, such as long reach hydraulic excavators, and equipment, such as backhoe loaders. 
It is important to note that over than $95 \%$ of the irrigation districts' infrastructure has been transferred to associations of users and that both infrastructure, machinery and equipment are insured to protect the investment of the federal government. Such infrastructure is composed as follows [3]:

- 139 storage dams

- 345 diversion dams

- 14,490 wells

- 345 pumping plants

- 29,918 miles of canals

- 19,364 miles of drains

- 43,593 miles of roads

- 2462 units of machinery and equipment for infrastructure maintenance

Table 1 presents a summary of the canal and drain characteristics, according to the bottom width and depth of water, as shown in Fig. 1.

Fig. 2 presents, graphically, the percentages within the national territory of canals and drains. The machinery and equipment are distributed as shown in the Fig. 3.

Approximately $60 \%$ of the irrigation district budget is allocated to maintenance works. A general distribution of the maintenance budget is presented in Fig. 4.

The infrastructure maintenance (conservation in Mexico) is an action to be performed periodically and permanently in order to preserve its state, under conditions closer to the original project.

Table 1: Canal and drain characteristics.

\begin{tabular}{|l|l|l|}
\hline Type & Bottom & Depth of water \\
\hline A & Between 32'9.7' and 65'7.4' & More than 9'10" \\
\hline B & Between 19'8.2' and 32'9.7' & Between 7'10.4' and 9'10" \\
\hline C & Between 13'1.4' and 19'8.2' & Between 5'7' and 7'10.4' \\
\hline D & Between 6'7' and 13'1.4' & Between 3'11.4' and 5'7' \\
\hline E & Less than 6'7' & Less than 3'11.4' \\
\hline
\end{tabular}

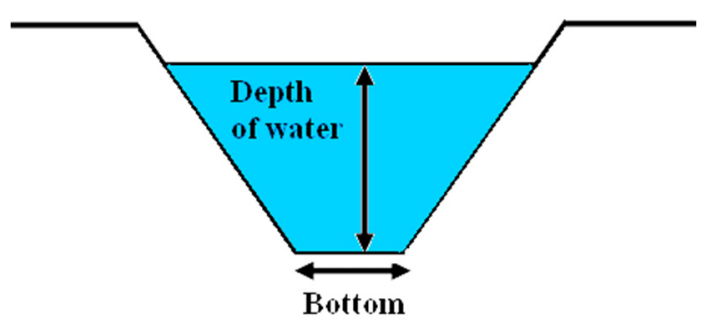

Figure 1: Canal and drain cross-section. 


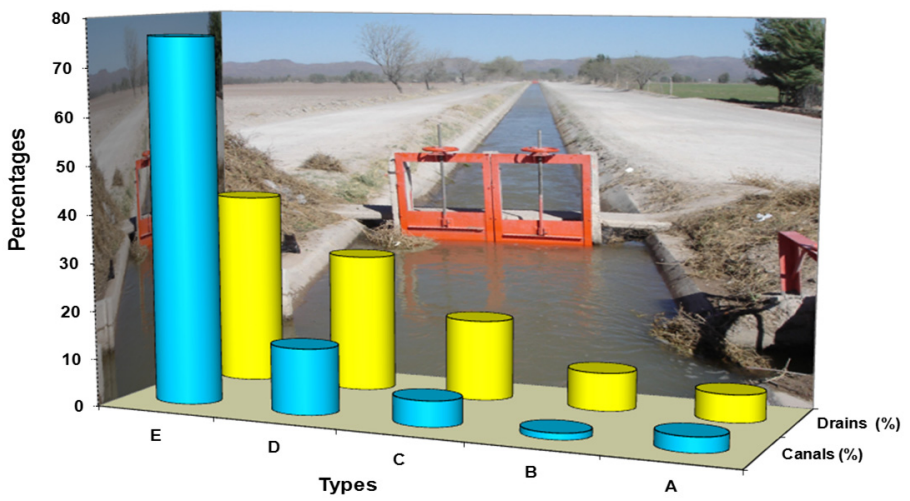

Figure 2: Percentages within the national territory of canals and drains.

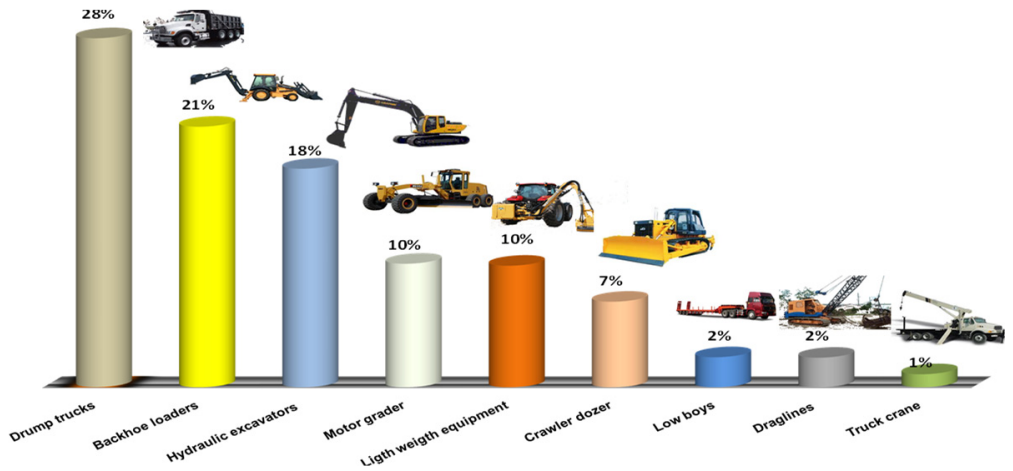

Figure 3: National inventory of machines and equipment in percentage.

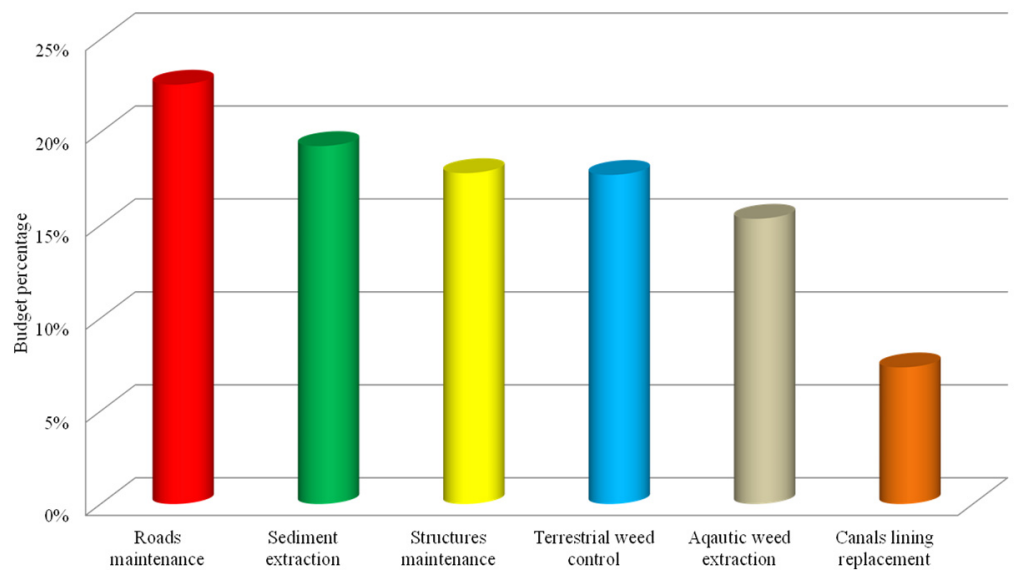

Figure 4: Maintenance budget distribution (\%). 


\section{SOLUTIONS}

To determine priorities the maintenance works scheduling will be based on engineering judgment, rational economy and considering the function and purpose of the infrastructure.

Irrigation districts needs methodologies for planning, scheduling, control and follow the maintenance activities.

\subsection{Technical annexes}

To accomplish the above, there are eight manuals called "Maintenance Technical Annexes for Irrigation Districts" which contains the activities must develop in a maintenance area in the irrigation districts and are designed to serve as an aid in the process of the maintenance program elaboration [4]. The main subjects included in the technical annexes are the follows:

Due the main purpose of maintenance works is to preserve the physical and operating characteristics of the infrastructure, the first activity is to elaborate the inventory of all structures to preserve the original characteristics.

Once the inventory is known, the next step is to quantify the types, amount and costs of works to keep in each structure defined in Mexico as "work concepts" which allow the elaboration of a budget, supported by volumes of the project and cost analysis (annexes include the procedure in excel format).

The procedure for performing the conservation work programs should consider the necessary times and dates of execution in each activity, based on irrigation and construction processes periods.

It is also necessary to update the machinery and equipment inventory to know the number and type of each machine and their physical conditions that allows determinate their yields per hour worked and annual hours to work in each concept.

To develop the machinery and equipment utilization program requires to know the necessary volumes, the execution period, the available machinery and the number of hours that must work.

The maintenance and repair machinery annual program is required to quantify the total cost of preventive maintenance, minor repairs and eventually full mechanical restoration per year.

Supervision of the works allows the verification of the execution of activities in accordance with the annual program and in the most appropriate way, making sure that the guidelines and the specifications are programmed.

With the monitoring of activities, according to the annual program, time deviations, weaknesses and inconsistencies in the formulation, implementation, execution and evaluation of the works are detected.

Due to certain extraordinary hydrometeorological phenomena, the main preventive measures to protect both infrastructure and machinery are provided.

$60 \%$ of the maintenance works in the irrigation districts are realized with machinery and equipment which will be in the adequate quantity and kind for the different work concepts. This is determined by a technical analysis called, in Mexico, "Machinery Balance" (necessary machinery and equipment) and a guide is included.

\subsection{Technical specifications for machinery and equipment acquisition}

In order to the associations of users can get the most suitable and economic machinery and equipment for infrastructure maintenance, there are 48 technical specifications and each one contains the following themes: 
- Technical aspects of engines and transmission.

- Information to be contained in manuals and catalogues.

- Recommended types of buckets for each kind of works.

- Location of subsidiaries to provide maintenance and service to the units.

- Operators and mechanics training request about the operation and maintenance of the units.

- Characteristics of the manufacturer's warranty required for each type of the machinery and equipment analysed.

With the participation of the technical staff of the National Water Commission, and the Mexican Institute of Water Technology, including experts from associations of users, one meeting takes place annually to actualize such specifications, as shown in Fig. 5.

Fig. 5 presents the participants (approximately 150) are integrated like a collegiate group to discuss resolutions about technical specifications for the most suitable and cost-effective machinery and equipment acquisition [5].

During such meetings the main manufacturers and distributors present the innovations of machinery and equipment for infrastructure maintenance, as shown in Fig. 6. The specifications are available for all the users of the National Water Commission Internet page.

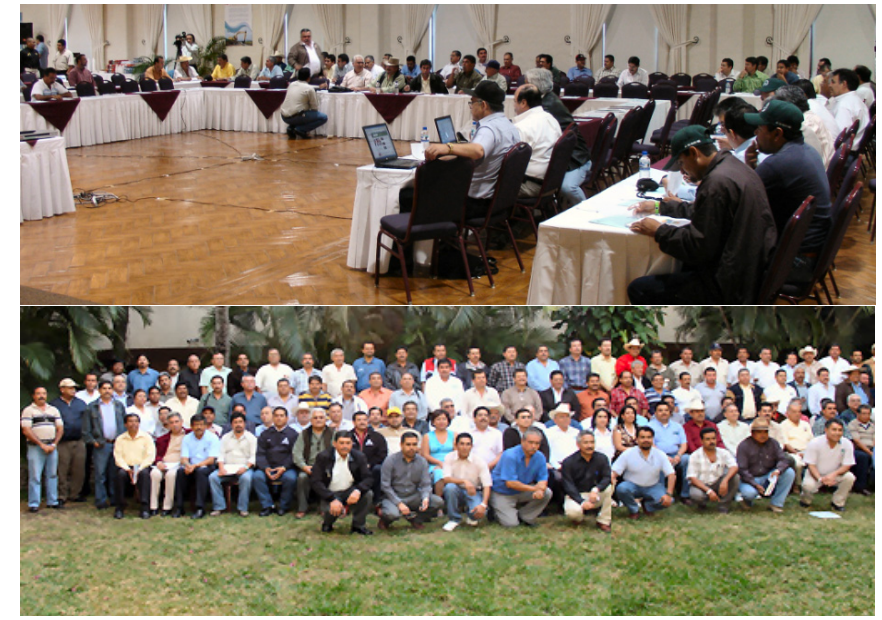

Figure 5: Technical staff at a meeting.

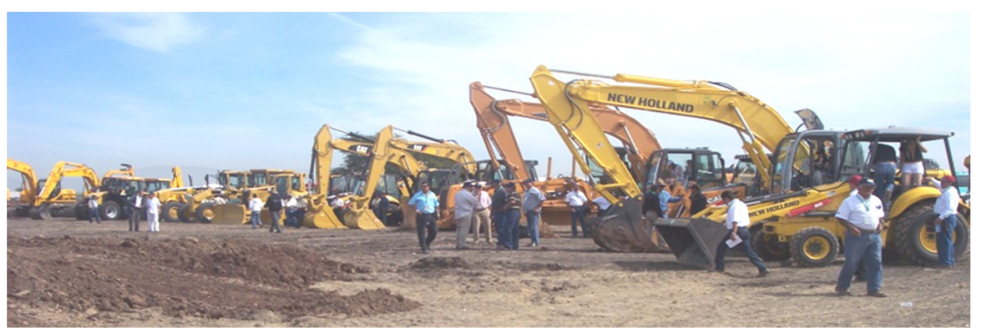

Figure 6: Presentation of innovations in maintenance machinery and equipment. 


\section{CONCLUSIONS}

The analysed solutions allow efficiently and economically the planning, scheduling and control of the works for the maintenance of infrastructure.

The agricultural production of the irrigation districts contributes directly in the development of the country because represents one third of the national food production, and involves over half a million of irrigation users. These products represent about $60 \%$ of the value of domestic production.

To maintain in optimal conditions, the infrastructure is essential to provide a good irrigation service, that is, to deliver water to crops timely and sufficient, which will get an optimum crop production.

Irrigation district productivity is directly related to maintenance works.

\section{RECOMMENDATIONS}

It is recommended to those countries with similar characteristics, to develop tools similar to those presented in this document since they have allowed the planning, scheduling and control of the works for the maintenance of infrastructure.

It is recommended to integrate a flexible, comprehensive and robust computer system that provides the appropriate tools for the capture, consultation and integration of the information recorded in the technical annexes, providing a solid and timely basis for decision-making at management level.

\section{REFERENCES}

[1] Water National Commission, Irrigated Areas and Volumes of Water Distributed in the Irrigation Districts Crop Year 2011 and 2012, 2013.

[2] Water National Commission, Statistics on Water in Mexico, 2014.

[3] Water National Commission, Inventories of Infrastructure, Machinery and Equipment of the Irrigation Districts, 2015

[4] Water National Commission, General Conservation of Infrastructure Technical Annexes, 2014.

[5] Water National Commission, Infrastructure Maintenance General Specifications for Machines and Equipment, 2015. 